\title{
ISOLAMENTO, DIFERENCIAÇÃO E ASPECTOS BIOQUÍMICOS DE CÉLULAS-TRONCO DE LÍQUIDO AMNIÓTICO
}

\author{
Antônio Carlos Vieira Cabral, Patrícia Caroline Ângelo, Henrique Vitor leite, Alamanda Kfouri Pereira, Ana Paula Brum Miranda lopes, Maria \\ Beatriz de Oliveira, Karina Braga Gomes Borges, Victor Cavalcanti Pardini, Alessandro Clayton de Sousa Ferreira* \\ Trabalho realizado pelo Departamento de Genética Humana e pela Criovida do Instituto H. Pardini, Belo Horizonte, Minas Gerais e no Hospital \\ das Clínicas e Faculdade de Farmácia da Universidade Federal de Minas Gerais, Belo Horizonte, MG
}

\author{
* Correspondência: \\ Instituto H. Pardini \\ Rua Maranhão, 1040 - \\ Funcionários \\ Belo Horizonte - MG \\ CEP 30150-331 \\ Tel./Fax: (31) 3287-3205 \\ alessandro@labhpardini.com.br
}

\section{RESUMO}

As células-tronco mesenquimais (MSCs) são células com grande potencial de diferenciação e estão sendo recentemente introduzidas na clínica para tratamento de várias doenças. Possuem várias vantagens incluindo sua estabilidade fenotípica in vitro.

OBjetIVo. isolamento das MSCs de líquido amniótico, sua expansão e a demonstraçãa da sua capacidade de se diferenciar em células miogênicas e adipogênicas, sem alterar a estabilidade cromossomal em meio de cultura.

Métodos. a fim de avaliar a mudança funcional destas células, foram avaliados parâmetros bioquímicos nas células adipogênicas já diferenciadas e antes da diferenciação através da dosagem de triglicérides. A diferenciação em células musculares foi avaliada comparando os níveis de creatinofosfoquinase - CK, desidrogenase lática - LDH e aldolase produzidas por estas células antes e após diferenciaçãa.

RESULTADOS. os níveis de trigilicérides foram significativamente maiores nas células diferenciadas, mostrando ainda a formação de grânulos intracitoplasmáticos. Todos os outros valores obtidos foram significativamente maiores nas células miogênicas diferenciadas quando comparadas às não diferenciadas.

Conclusão. os resultados sugerem que estes protocolos podem ser usados para avaliar diferenciação de células-tronco em células adipogênicas e miogênicas, e que o líquido amniótico pode ser uma fonte para obtenção destas células.

UnITERMOS: Células-tronco mesenquimais. Líquido amniótico. Triglicérides. Creatinofosfoquinase (Creatina quinase). Desidrogenase lática (L-lactato desidrogenase). Aldolase (Frutose-bifosfato aldolase).

\section{INTRODUÇÃO}

As células-tronco são definidas como células com grande capacidade de diferenciação. Durante o desenvolvimento embrionário, as células-tronco do blastocisto dão origem às células progenitoras que se tornam progressivamente restritas às células especializadas. As célulastronco também estão presentes em tecidos maduros, sendo denominadas de células-tronco adultas, e também contribuem para o desenvolvimento pós-natal por substituir células já diferenciadas que são perdidas devido à injúria, apoptose programada ou "turnover" fisiológico'. As células-tronco adultas não somente possuem a capacidade multipotente, como também pluripotente, como foi demonstrado em trabalhos com camundongos, no qual células-tronco hematopoiéticas derivadas da medula óssea foram capazes de regenerar tecido muscular esquelético lesionado quimicamente ${ }^{2}$. Neste mesmo trabalho também foi possível verificar a capacidade dessas células de migrarem da medula para as regiões lesionadas.

As células-tronco mesenquimais (CTM) correspondem a uma população de células progenitoras multipotentes capazes de atuarem na hematopoiese e se diferenciarem em tecidos mesenquimais, como células das linhagens osteogênica, adipogênica e condrogênica,
Estas células têm sido utilizadas com bastante otimismo na medicina regenerativa e engenharia tecidual, como o desenvolvimento de células musculares, regeneração hepática e formação de células do sistema nervoso central $\left.\right|^{5}$. Aliado à possibilidade de ser possível isolar e diferenciar as CTM em meio de cultura, o uso em estudos clínicos e pré-clínicos tem demonstrado seu alto poder terapêutico.

A fonte de CTM mais utilizada é a medula óssea, no entanto, como o número e a capacidade de diferenciação destas células diminuem com a idade, seu potencial terapêutico também declina com o tempo ${ }^{6}$. Assim, devido a estas limitações, outras fontes de CTM foram identificadas, sendo possível isolá-las em trabéculas ósseas, tecido adiposo, líquido sinovial, sangue periférico e musculoesquelético ${ }^{5}$.

Hoje a maioria dos procedimentos clínicos de transplante de células-tronco tem utilizado como fonte células extraídas de sangue de cordão umbilical', o qual, no entanto, tem demonstrado baixa freqüência de células progenitoras mesenquimais ${ }^{8}$.

Sabe-se que o líquido amniótico contém múltiplos tipos celulares derivados do feto em desenvolvimento e alguns autores têm demonstrado que as células de líquido amniótico expressam genes embrionários como o OCT-4, que é responsável pelo caráter pluripotente de células-tronco embrionárias?. Além disso, o líquido amniótico possui 
como vantagem a facilidade de obtenção, uma vez que a amniocentese é um procedimento utilizado rotineiramente como método de propedêutica fetal e associa-se a um número pequeno de complicações. É também conhecida a proibição ético-legal da manipulação de células embrionárias, mesmo que com fins terapêuticos.

Assim, este trabalho teve como objetivo o isolamento de CTM em líquido amniótico, sua expansão (multiplicação) in vitro, além da demonstração da capacidade em se diferenciarem em células com características adipogênicas e miogênicas, produzindo mediadores bioquímicos característicos. Desta maneira, a diferenciação celular pode ser evidenciada de forma rápida e reprodutível. Além disso, buscou-se avaliar a estabilidade cromossômica das células mesenquimais em cultura após o processo de expansão.

Além disso, foi demonstrado que o líquido amniótico apresenta-se como uma nova fonte de CTM com grande potencial de proliferação e diferenciação, sem interferir no processo de cariotipagem fetal, podendo ser no futuro a fonte de escolha para a obtenção destas células e suas aplicações terapêuticas.

\section{Métodos}

\section{Amniocentese}

Aproximadamente $5 \mathrm{~mL}$ de líquido amniótico foram coletados em cinco gestantes, com indicação clínica para o procedimento, através de punção de abdome com agulha BD-20G. Antes da punção foi realizado procedimento de anti-sepsia com solução povidina-iodo tópico e anestesia local do abdome materno por todo o trajeto da agulha utilizando-se lidocaína I\% sem vasoconstritor (Astraß).

O procedimento foi realizado após a obtenção do consentimento informado de todas as pacientes e o estudo teve a aprovação do Comitê de Ética em Pesquisa (COEP) da Universidade Federal de Minas Gerais.

\section{Cultura de células}

Para obtenção e cultivo de células mesenquimais, foram testados dois diferentes meios de cultura, o meio Chang's (Irvine Cientific $®$ ) suplementado com soro fetal bovino e L-glutamina; e o meio Amniomax (Invitrogen $囚$ ) com os mesmos suplementos.

Para a realização das culturas, $5 \mathrm{~mL}$ de líquido amniótico foram centrifugados em tubos cônicos de $15 \mathrm{~mL}$ (Corning ${ }^{\circledR}$ ) a $1.000 \mathrm{rpm}$ por 8 a 10 minutos. Os sobrenadantes foram descartados e o precipitado de células foram ressuspendidos em $5 \mathrm{~mL}$ de meio de cultura Chang's ou Amniomax. Os tubos cônicos foram gentilmente homogeneizados e seu conteúdo transferido para frascos T25. Os frascos foram incubados a $37^{\circ} \mathrm{C}$ e $5 \%$ de $\mathrm{CO} 2$ durante 4 a 5 dias. Após este período foi realizada a troca dos meios de cultura. Depois de atingirem uma confluência de 80\%, as células foram tratadas com tripsina (Gibcoß), e a partir daí foram utilizadas para diferenciação ou expansão.

\section{Expansão celular}

As células da cultura primária foram centrifugadas em tubo cônico de $15 \mathrm{~mL}$, ressupendidas em meio Chang's e Amniomax e replaqueadas em frascos de $T 25$, sendo este procedimento repetido por três vezes.

\section{Diferenciação celular}

Para diferenciaçãa das células em células adipogênicas, foram acrescentados ao meio de cultura: dexametasona (I mol/L, Ache $\left.{ }^{\circledR}\right)$, teofilina $(0,5 \mathrm{mmol} / \mathrm{L}$, Abbott $囚)$, insulina $(10 \mathrm{mg} / \mathrm{L}$, Sigma $囚)$ e indometacina $(200 \mathrm{mmol} / \mathrm{L}$, Merck®). Já para a diferenciação em células miogênicas foi acrescentado aos meios de cultura DMSO (Merck®) com concentração final de I\%v/v ou DMSO acrescido de ácido ascórbico na mesma concentraçãa. As células foram mantidas em cultura a $37^{\circ} \mathrm{C}$ a $5 \%$ de $\mathrm{CO} 2$. Os meios de cultura com os insumos foram trocados a cada dois dias.

\section{Cariotipagem}

Ao final da quarta passagem, as células obtidas foram novamente tratadas com tripsina, ressuspendidas, centrifugadas e fixadas com uma solução 3:I de etanol/ácido acético (Merck®). O pacote celular final foi então submetido ao procedimento de cariotipagem com banda $\mathrm{G}$ a fim de avaliar se as divisões celulares in vitro provocaram algum tipo de alteração cromossômica.

\section{Avaliação da diferenciação celular}

A diferenciação em células adipogênicas foi avaliada pela dosagem de triglicérides pelo método enzimático colorimétrico utilizando o aparelho ADVIA 2400 (Bayer ${ }^{\circledR}$ ), de acordo com o protocolo do fabricante. A diferenciação em células miogênicas foi avaliada através das dosagens de creatinofosfoquinase, desidrogenase lática e aldolase, ambas pelo método enzimático utilizando o mesmo equipamento e protocolo padrão.

\section{Análise estatística}

Para a análise estatística, foi considerado um intervalo de confiança de $95 \%$ e uma diferença significativa $s e \quad p \leq 0,05$. As variáveis quantitativas foram analisadas utilizando-se o teste t para comparação de médias de grupos independentes. As análises foram realizadas através do programa Sigma Stat ${ }^{10}$.

\section{Resultados}

\section{Cultura de célula}

Em ambos os meios de cultura (Chang's e Amniomax), após cinco dias de cultivo, foi possível observar células com aspecto fibroblastóide aderidas ao fundo frasco T25. Neste período, o meio Amniomax mostrou-se mais eficiente por promover uma maior multiplicação celular em todas as amostras cultivadas. Após 10 dias de cultivo, as células já se mostravam com confluência maior que $80 \%$ com aspecto característico fibroblastóide (Figura I).

\section{Cariotipagem}

A fim de avaliar se a cultura celular induziu alguma alteração cromossômica, foi realizada a cariotipagem das células obtidas logo após amniocentese e comparada aos resultados do cariótipo das células em cultura após três passagens. Três amostras em cultura apresentaram um cariótipo sem alterações (duas amostras 46, XY e uma amostra 46, $X X$ ), o qual foi compatível com o sexo fetal. Foi observado que uma das amostras apresentava trissomia do cromossomo 18 (Figura 2A) e outra correspondia a uma amostra triplóide (Figura 2B). Estes 
resultados foram compatíveis com os obtidos antes da cultura celular, mostrando que estas alterações numéricas não foram induzidas in vitro, - que já era esperado, pelo fato das mulheres submetidas à amniocentese já apresentarem condições clínicas que justificassem o procedimento.

\section{Diferenciação celular}

As culturas celulares antes e após indução foram tratadas com tripsina, ressuspendidas em I mL de tampão Hank's (Gibcoß) e lisadas mecanicamente através de ultra-som. Em seguida, as células lisadas foram centrifugadas à $14.000 \mathrm{rpm}$ durante cinco minutos e o sobrenadante foi submetido às dosagens.

A diferenciação em células adipogênicas começou a ser percebida após dois dias de indução com os fatores de diferenciação acima mencionados. Foi observada mudança na morfologia das células, as quais adquiram aspecto arredondado quando comparado ao aspecto fibroblastóide inicial e um acúmulo de grânulos intracitoplasmáticos (Figura 3).

A avaliação da diferenciação adipogênica foi realizada através da dosagem de triglicérides na cultura de células lisadas. As células préindução mostraram níveis indetectáveis de triglicérides. Já as células adipogênicas induzidas mostraram níveis significativamente elevados com média de 129,62 \pm 8;71 mg/dL $(p=0,00)$.

A diferenciação em células miogênicas só foi obtida em meio de cultura acrescido do DMSO isoladamente (Figura 4) e foi avaliada através da dosagem bioquímica de creatinofosfoquinase - CK (37.2 土 13,84 U/L), desidrogenase lática - LDH (379.2 \pm 240,76 U/L) e aldolase (59.18 $\pm 31,96 \mathrm{U} / \mathrm{L}$.) As células não induzidas mostraram baixos valores destes analitos: CK (4.6 $\pm 5.94 \mathrm{U} / \mathrm{L}), \mathrm{LDH}(43.2 \pm$ $31.96 \mathrm{U} / \mathrm{L})$ e aldolase $(1.34 \pm 1.16 \mathrm{U} / \mathrm{L})$, quando comparados aos valores obtidos após indução. Os valores mostram uma diferença significativa entre os resultados obtidos nas culturas celulares antes e após indução (CK: $p=0.0013$; LDH: $p=0.015$; aldolase: $p=0.0037$ ).

\section{Discussão}

Recentemente, vários trabalhos têm sido publicados com o intuito de identificar, caracterizar e diferenciar células-tronco de fontes diversas. Estes trabalhos têm demonstrado a característica de pluripotência destas células com potencial terapêutico para tratamento de patologias tanto intra-útero quanto após o nascimento ${ }^{11,12,13}$.

A diferenciação destas células tem sido principalmente demonstrada por técnicas moleculares e por ensaios citológicos e histológicos utilizando colorações especiais como Oil Red e Von Kossa. Entretanto, em nenhum destes trabalhos foram evidenciadas alterações das funções bioquímicas das células diferenciadas oriundas de líquido amniótico. A importância do presente trabalho consiste no fato de que as alterações ocorridas nas células diferenciadas foram demonstradas não só nas suas características morfológicas, mas essencialmente na mudança funcional evidenciada pelas análises bioquímicas.

Desta forma, cinco amostras de líquido amniótico foram coletadas e cultivadas em meio de cultura para proliferação. As condições do cultivo foram padronizadas neste trabalho, no qual se observou que o meio Amniomax permitiu a obtenção de um resultado mais eficiente sendo observado um tempo menor de cultura para confluência celular de $80 \%$.

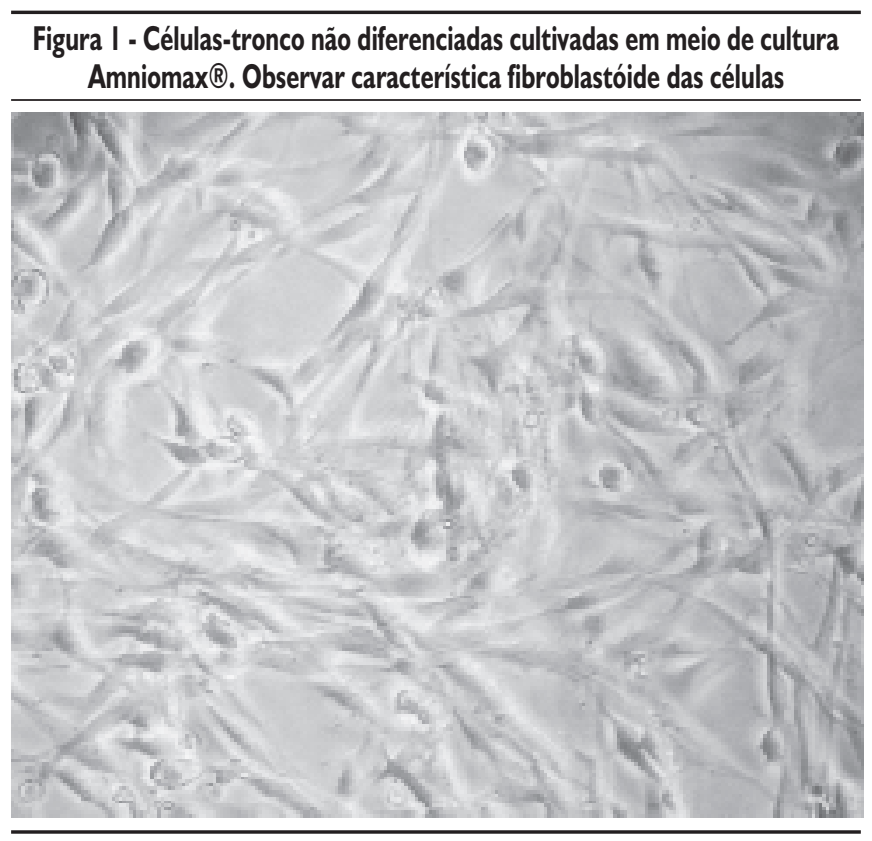

\section{Figura 2A- Cariótipo com Banda $\mathbf{G}$ de uma das amostras analisadas em cultura após três passagens mostrando trissomia do cromossomo 18}

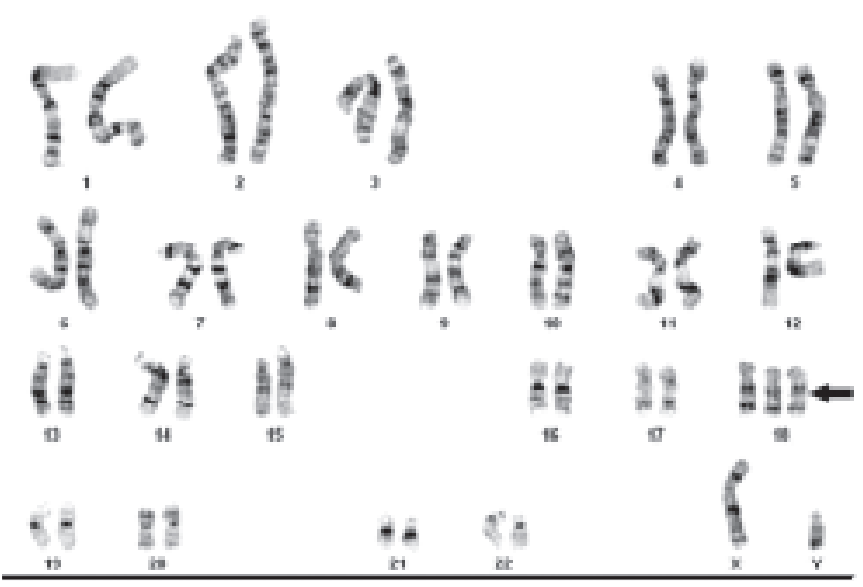

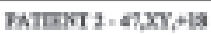

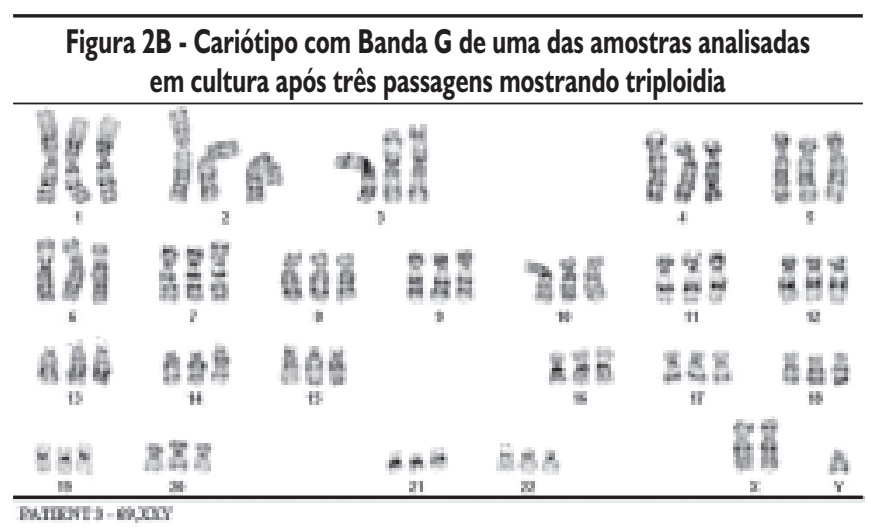




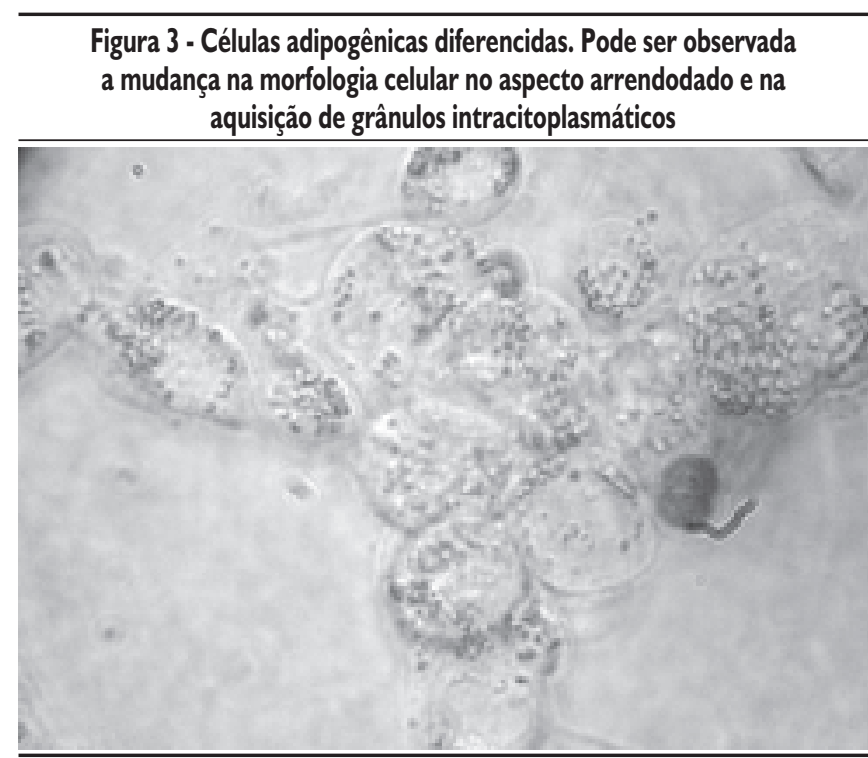

Nas culturas não foram utilizados fatores exógenos de crescimento como bFGF, aFGF, visto que estes fatores podem levar a possíveis mutações cromossômicas in vitro. A ausência de aneuploidias e/ou poliploidias foi evidenciada através da cariotipagem nas culturas de quarta passagem. A cariotipagem demonstrou ainda que não ocorreu contaminação do material coletado com células maternas, pois em culturas de fetos sabidamente masculinos, o cariótipo confirmou ploidia normal e presença de cromossomo $Y$.

As condições de diferenciação das células em cultivo em células adipogênicas foram adaptadas substituindo a isobutil-metil-xantina (IBMX), comumente utilizada em vários trabalhos ${ }^{14,15}$ por teofilina, outro inibidor de fosfodiesterase. Em virtude dos resultados obtidos, pode-se considerar a teofilina como possível substituto para o IBMX.

Neste trabalho procurou-se verificar mudanças bioquímicas nas células induzidas à diferenciaçãa adipogênica pela dosagem de triglicérides. Nas células diferenciadas foi possível observar a nova capacidade em produzir triglicérides, caracterizando assim o ganho de uma nova função, e possivelmente armazená-los sob a forma de grânulos intracitoplasmáticos observados nestas células à microscopia. A possibilidade de que este valor obtido seja proveniente do meio de cultura e outros fatores utilizados na diferenciação poderá ser descartada, uma vez que todos os suprimentos isoladamente foram submetidos à mesma dosagem e nenhum valor foi detectado.

Uma nova etapa na diferenciação celular foi conduzida com o intuito de avaliar sua transformação em células miogênicas. Para isto, foram testados os meios de cultura enriquecidos com DMSO e ácido ascórbico, e num segundo momento, apenas com DMSO. Observouse que no primeiro caso não houve crescimento celular quando observadas as culturas em 14 dias, mas contrariamente a este resultado, a adição do DMSO isoladamente ao meio de cultura conferiu um resultado satisfatório onde se observou grande confluência de células.

A fim de avaliar a mudança funcional destas células, foram comparados os valores obtidos das células diferenciadas e não diferenciadas

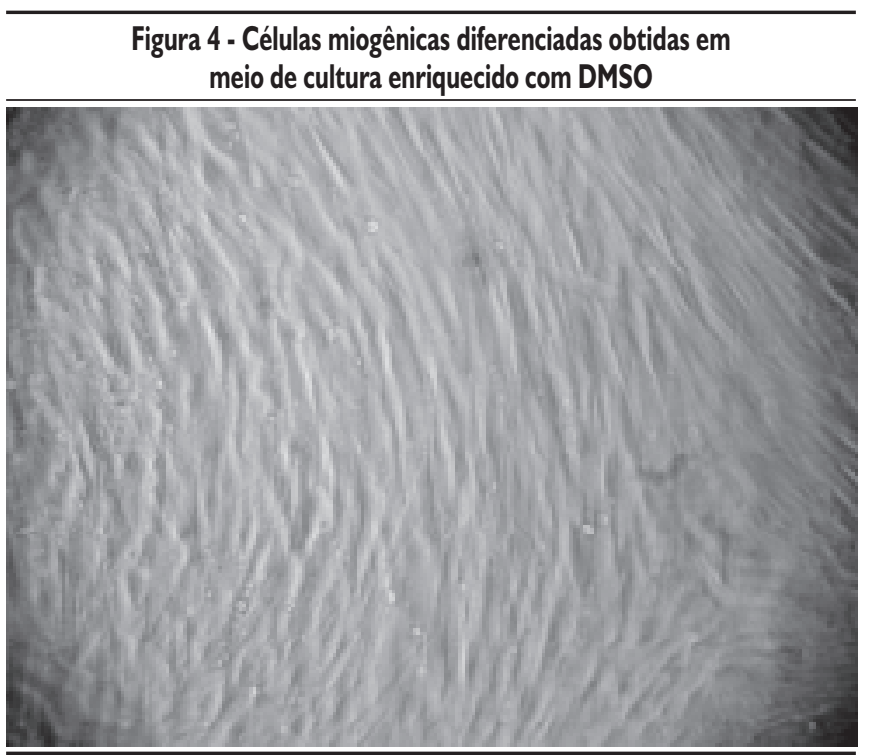

para três analitos: CK, LDH e aldolase. Estas enzimas são produzidas especialmente em células musculares. Quando analisadas em conjunto, elas dão uma idéia da natureza miogênica das células analisadas.

Em todos os analitos dosados foram observadas diferenças significativas entre as células pré diferenciação e células miogênicas, sugerindo que o protocolo de diferenciação padronizado neste trabalho poderá ser utilizado na obtenção de células com características de células musculares.

\section{Conclusão}

A obtenção de células adipogênicas e miogênicas in vitro surge como um fator de grande relevância e a possibilidade de utilizar o líquido amniótico como fonte de obtenção de CTM abre novas perspectivas de tratamento que poderão no futuro ser a chave para o tratamento e cura de várias doenças.

\section{Agradecimento}

Fundação de Amparo à Pesquisa do Estado de Minas Gerais - FAPEMIG

\section{Conflito de interesse: não há}

\section{SUMMARY}

\section{ISOLATION, DIFFERENTIATION AND BIOCHEMICAL ASPECTS OF AMNIOTIC FLUID STEM CELL}

The mesenchymals stem cells (MSCs) are cells with the great potential of differentiation are being introduced in the clinic for treatment of several diseases. Mesenchymal stem cells have several advantages including the stability of their phenotype in vitro. Background: isolation of MSCS in amniotic fluid, its expansion and the demonstration of the capacity of these cells to differentiate in adipogenic and miogenic cells, without to change the chromosomal stability of the MSCs in culture. Methods: in order to evaluate the functional change of these cells, were gotten values of the 
differentiated adipogenic cells and not differentiated through the dosage of triglycerides. The miogenic nature of the differentiated cells was analyzed comparing the creatine kinase - $C K$, lactic dehydrogenase - $L D H$ and aldolase produced by the cells. Results: the values of triglycerides were significantly higher in differentiated cells, showing intracitoplasmatic granule form after differentiation. All the biochemical characters were significantly higher in differentiated miogenic cells. Conclusions: this study suggests that the standardized protocol of differentiation can be used in the attainment of cells with characteristics of adipogenic and muscular cells, from amniotic fluid. [Rev Assoc Med Bras 2008; 54(6): 489-93]

KEY WorDS: Mesenchymals stem cells. Amniotic fluid. Triglycerides. Creatine kinase. Lactic dehydrogenase (L-lactato desidrogenase). Aldolase (Fructose-biphosphate aldolase).

\section{REFERÊNCIAS}

I. De Bari C, Dell'Accio F, Tylzanowski P, Luyten F. Multipotent mesenchymal stem cells from adult human synovial membrane. Arthritis Rheum. 200 I;44: 1928-42.

2. Ferrari G, Cusella G, Angelis D, Coletta M, Paolucci E, Stornaiuolo A. Muscle Regeneration by Bone-Marrow Derived Myiogenic Progenitors. Science. 1998;279: I 528-30.

3. Barry F, Murphy M. Mesenchymal stem cells: clinical applications and biological characterization. Int J Biochem Cell Biol. 2004;36:568-84.

4. Bieback K, Kern S, Klüter H, Eichler H. Critical parameters for the isolation of mesenchymal stem cells from umbilical cord blood. Stem Cells. 2004;22:625-34.

5. Minguell J, Erices A, Conget P. Mesenchymal stem cells. Exp Biol Med. 2001;226:507-520
6. Mueller S, Glowacki J. Age-related decline in the osteogenic potential of human bone marrow cells cultured in three dimensional collagen sponges. J Cell Biochem. 200 I;82:583-90.

7. Lee O, Kuo T, Chen W, Lee K, Hsieh S, Chen T. Isolation of multipotent mesenchymal stem cells from umbilical cord blood. Blood. 2004; 103:1669-75.

8. Wexler S, Donaldson C, Denning-Kendall P. Adult bone marrow is a rich source of human mesenchymal stem cells but umbilical cord and mobilized adult blood are not. Br J Haematol. 2003; 121:368-74.

9. Miki T, Lehmann T, Cai H, Stolz D, Strom S. Stem cell characteristics of amniotic epithelial cells. Stem Cell. 2005;23: I 549-59.

10. Tuttle A, Katz A, Bridenbaugh O, Quinlan R, Knarr D. A double-blind comparison of the abdominal wall relaxation produced by epidural $0.75 \%$ ropivacaine and $0.75 \%$ bupivacaine in gynecologic surgery. Reg Anesth. 1995;20:515-20.

I I. ODonoghue K, Chan J. Human fetal mesenchymal stem cells. Curr Stem Cell Res Ther. 2006; 1:371-86.

12. Flake A. In utero stem cell transplantation. Best Pract Res Clin Obstet Gynaecol. 2004; I 8:94I-58.

13. Muench M, Bárcena A. Stem cell transplantation in the fetus. Cancer Control. 2004; I I: 105- I8.

14. Lee R, Kim B, Choi I, Kim H, Choi H, Suh K, et al. Caracterization and expression analysis of mesenchymal stem cells from human bone marrow and adipose tissue. Cell Physiol Biochem. 2004; I 4:3 I I-24.

15. Portmann-Lanz C, Schoeberlein A, Huber A, Sager R, Malek A, Holzgreve $W$, et al. Placental mesenchymal stem cells as potential autologous graft for pre- and perinatal neurodegeneration. Am J Obstet Gynecol. 2006; 194:664-73

Artigo recebido: 27/02/07

Aceito para publicação: 24/03/08 